\title{
The effect of deep venous thrombosis on oxidative damage and vitamin A and beta-carotene levels
}

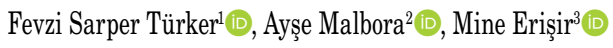 \\ ${ }^{1}$ Department of Cardiovascular Surgery, University of Health Sciences, Elazlğ Training and Research Hospital, Elazl̆̆, Turkey \\ ${ }^{2}$ Department of Physiotherapy and Rehabilitation, Bitlis Eren University, Health High School, Bitlis, Turkey \\ ${ }^{3}$ Department of Biochemistry, Firat University Faculty of Veterinary Medicine, Elazl ̌̆, Turkey
}

\begin{abstract}
Objectives: This study aims to investigate the effect of deep venous thrombosis (DVT) on oxidative damage, vitamin A, and beta-carotene levels.

Patients and methods: A total of 50 DVT patients (29 females, 21 males; mean age 48 years; range, 20 to 75 years) who were admitted to the cardiovascular surgery clinic of Elazığ Training and Research Hospital with acute ( $<2$ weeks) or chronic $(\geq 4$ weeks) DVT and 100 healthy individuals (54 females, 46 males; mean age 46 years; range, 16 to 69 years) between January 2018 and July 2018 were included. Malondialdehyde, vitamin A, and beta-carotene levels in plasma of peripheral blood samples were analyzed.

Results: Demographic characteristics of the acute and chronic DVT patients were similar ( $p>0.05)$. In all DVT patients having thrombosis in the distal and proximal leg veins, the mean malondialdehyde (MDA) levels significantly increased and the mean levels of vitamin A significantly decreased, compared to healthy controls $(\mathrm{p}<0.05)$. No significant difference was found in vitamin A levels and demographic characteristics between acute and chronic DVT patients ( $p>0.05)$.
\end{abstract}

Conclusion: Our study results suggest that decreased vitamin A levels may play a role in the development of DVT.

Keywords: Beta-carotene, deep venous thrombosis, malondialdehyde, oxidative stress, vitamin A.

Venous thrombosis is one of the major causes of morbidity and mortality worldwide and occurs in one of 1,000 individuals in industrialized countries. ${ }^{[1]}$ The anticoagulant therapy used for this condition is associated with bleeding side effects, although it is both preventive and therapeutic. ${ }^{[2]}$ Therefore, a preventive treatment strategy is required in the follow-up of venous thrombosis without the use of anticoagulants. In the basic and research-based studies conducted for this purpose, several hypotheses have been established that vitamins can prevent venous thrombosis. ${ }^{[3,4]}$ However, most of these studies have focused on arterial thrombosis. ${ }^{[5-7]}$ The number of studies on venous thrombosis is very limited and, in some trials, it has been shown that vitamin $\mathrm{D}$ and $\mathrm{E}$ supplementations can reduce the risk of venous thrombosis. ${ }^{[8,9]}$ On the other hand, other studies have reported no effect. ${ }^{[10]}$

Vitamin A is a fat-soluble non-enzymatic agent and is effective in low oxygen concentrations. It has also an important role in maintaining the normal permeability and integrity of the vitamin A cell membrane. ${ }^{[11]}$ All-trans retinoic acid (ATRA), the active metabolite of vitamin $A$, can modulate tumor-associated prothrombotic mechanisms considered relevant for the pathogenesis the hypercoagulable state associated with malignant disease. The vascular endothelium also plays a key role in determining the plasma fibrinolytic activity by synthesizing both tissue-type plasminogen activator ( $\mathrm{t}-\mathrm{PA})$ and its specific inhibitor

Received: November 13, 2019 Accepted: February 11, 2020 Published online: March 11, 2020

Correspondence: Fevzi Sarper Türker, MD. SBÜ Elazı̆g Eğitim ve Araştırma Hastanesi Kalp ve Damar Cerrahisi Kliniği, 23280 Elazığ, Türkiye. e-mail: sarperturker@gmail.com 
plasminogen activator inhibitor-1 (PAI-1). Circulating t-PA, which is predominantly responsible for plasma fibrinolytic potential, is mainly derived from vascular wall, where it is localized in endothelial cells. It has been demonstrated that ATRA induces expression of t-PA in human umbilical vein endothelial cells without having a marked influence on the PAI- 1 synthesis. The human t-PA gene is thought to be modulated by the retinoic acid. ${ }^{[12]}$ Retinoic acid increases t-PA production by more than 2.5 times. ${ }^{[13]}$

In the literature, a limited number of vitamin A applications is available in venous thrombosis. ${ }^{[14]}$ However, there is no study on the effect of vitamin $A$ and beta $(\beta)$-carotene levels in the formation of venous thrombosis. According to the studies of vitamin A application, vitamin $\mathrm{A}$ has shown antioxidant effects in low oxygen presence, ${ }^{[11]}$ and retinoic acid increases the fibrinolysis effect by increasing t-PA production. ${ }^{[12]}$ In recent studies, it has been additionally reported that increased reactive oxygen species (ROS) have an important role in hypertension, arteriosclerosis, abdominal aortic aneurysms, and venous pathologies. ${ }^{[15]}$ Serum malondialdehyde (MDA) is widely accepted as an indicator for lipid peroxidation and free radical activity. ${ }^{[16]}$ Due to the limited researches and previous study results in this topic, we aimed to investigate the effect of deep venous thrombosis (DVT) on oxidative damage, vitamin $A$, and $\beta$-carotene levels.

\section{PATIENTS AND METHODS}

A total of 50 DVT patients (29 females, 21 males; mean age 48 years; range, 20 to 75 years) who were admitted to the cardiovascular surgery clinic of Elazığ Training and Research Hospital with acute ( $<2$ weeks) or chronic ( $\geq 4$ weeks) DVT and 100 healthy individuals (54 females, 46 males; mean age 46 years; range, 16 to 69 years) between January 2018 and July 2018 were included in this study. Those with chronic renal insufficiency and advanced age ( $\geq 75$ years), those receiving active cancer treatment, and long-bedridden patients were excluded. Acute DVT diagnosis was made in the outpatient or emergency setting based on the medical history, presence of positive Homans' sign and lower extremity venous Doppler ultrasound (DUS). Their DVT treatment during taking blood samples was recorded. Venous DUS results were obtained from the digital recording systems. The control group was selected by the treating physicians, nurses, and other health care personnel working in the hospital.
A written informed consent was obtained from each participant. The study protocol was approved by the Ethics Committee of Firat University, Faculty of Medicine (No. 2017-25). The study was conducted in accordance with the principles of the Declaration of Helsinki.

\section{Blood sampling and biochemical analyses}

Blood samples were taken from the peripheral veins into tubes containing heparin. The heparinized blood was centrifuged at 3,000 rpm for $5 \mathrm{~min}$ and its plasma was separated. Then, it was kept at the freezer at $-80^{\circ} \mathrm{C}$ until biochemical analysis.

Using the lipid peroxidation assay method, the MDA in plasma was analyzed based on the method of Placer et al. ${ }^{[17]}$ with slight modifications. The MDA formed a pink complex with thiobarbituric acid (TBA), and the absorbance was read at $532 \mathrm{~nm}$. The plasma MDA content was expressed in $\mathrm{nmol} / \mathrm{mL}$.

For the vitamin $A$ and $\beta$-carotene analyses, vitamin A (retinol) and $\beta$-carotene concentrations were measured chemically. A total of $1 \mathrm{~mL}$ of each serum sample was mixed with $1.0 \mathrm{~mL}$ of ethanol containing butylated hydroxytoluene in a test tube, then $3 \mathrm{~mL}$ hexane was added. Tubes were shaken for $10 \mathrm{~min}$ and centrifuged at $800 \times \mathrm{g}$ for $10 \mathrm{~min}$. The supernatants were measured at double wavelength at $453 \mathrm{~nm}$ (for $\beta$-carotene) and at $325 \mathrm{~nm}$ (Vitamin A) and final concentrations were calculated by equations according to the method described by Suzuki and Katoh. ${ }^{[18]}$

\section{Statistical analysis}

The minimum sample size yielding a power value of $80 \%$ (under 0.25 minimum difference and 0.42 standard deviation) was accepted as the

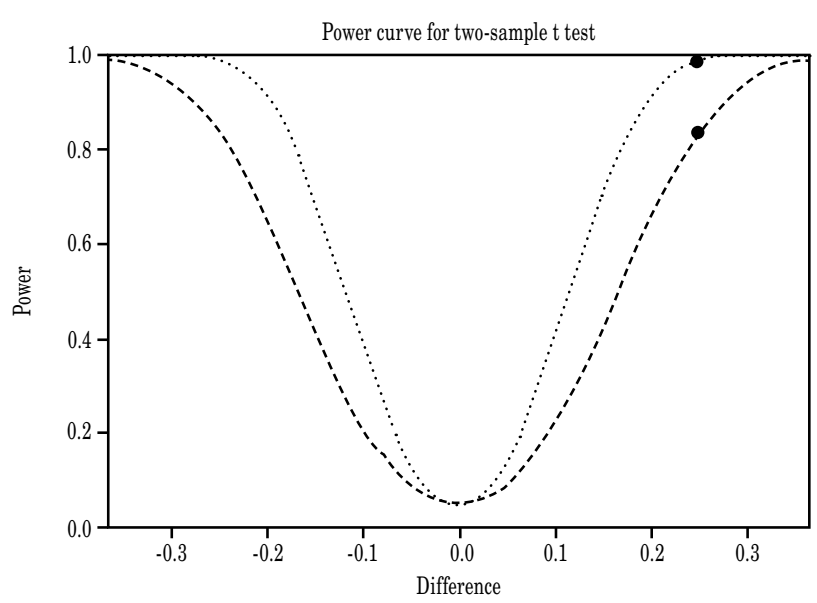

Figure 1. Power curve of the patient and control groups. 


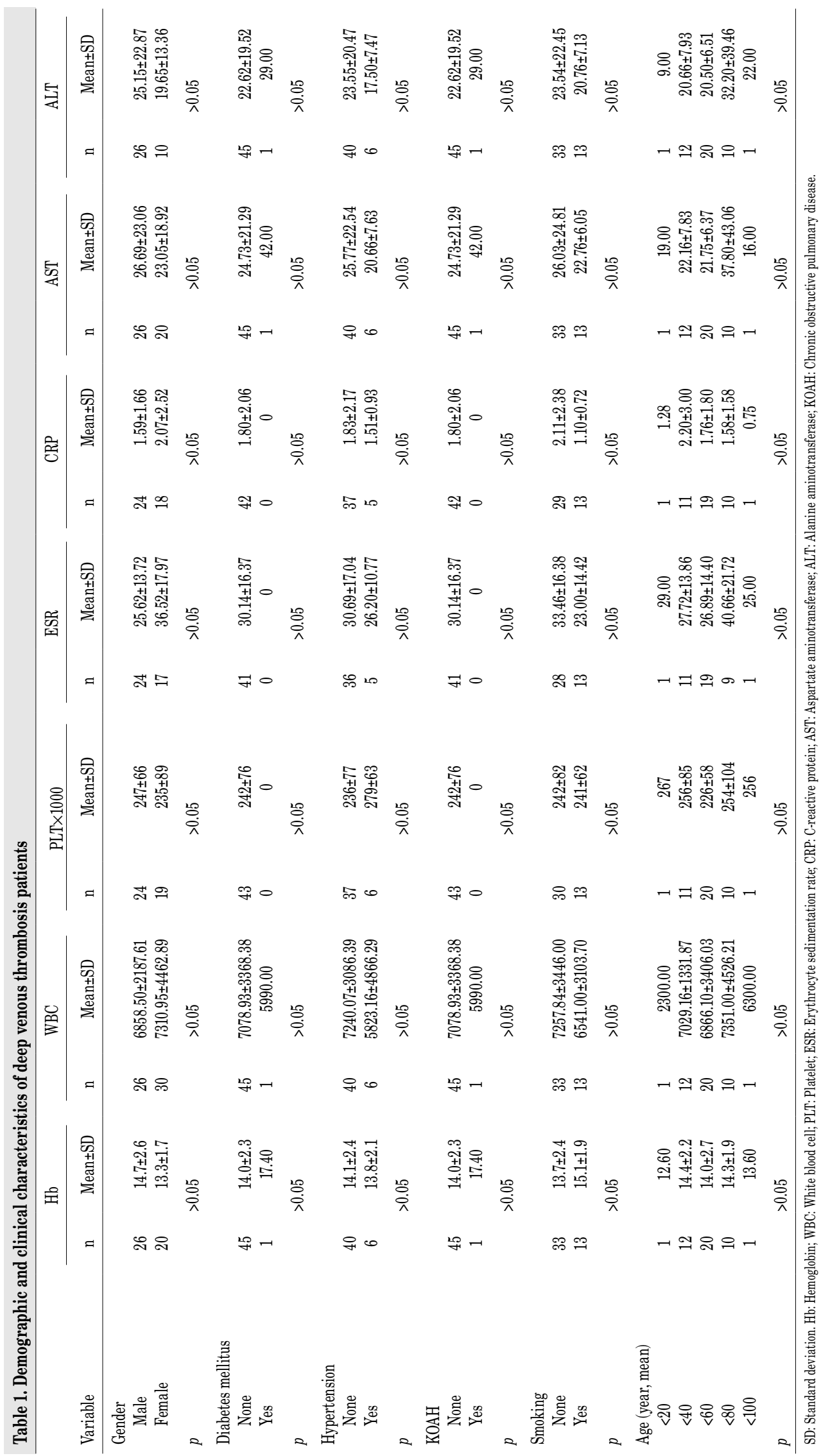


optimum sample size. The Minitab ${ }^{\circledR} 19$ powerful statistical software (Microsoft Inc., PA, USA) was carried out for the calculation of the optimal sample size under considered conditions. Power curve is shown in Figure 1.

Statistical analysis was performed using the SPSS for Windows version 15.0 software (SPSS Inc., Chicago, IL, USA). Descriptive data were expressed in mean \pm standard deviation (SD), median (min-max), or number. For the comparison of DVT patients with healthy individuals, independent sample t-test was used. The Mann-Whitney $U$ test was used to compare distal and proximal DVT patients versus healthy individuals. Analysis of means (ANOM) technique was used to optimize the parameters. ${ }^{[19,20]}$ Demographic data of DVT patients were evaluated using the independent sample t-test. A $p$ value of $<0.05$ was considered statistically significant.

\section{RESULTS}

In the control group consisting of healthy individuals; three were under the age of 20, 25 people were between 21 and 30 years, 38 were between

\begin{tabular}{lcc}
$\begin{array}{l}\text { Table 2. Distribution of deep venous thrombosis patients according to } \\
\text { gender and anticoagulants }\end{array}$ & Female (n) & Male (n) \\
\hline & 2 & 7 \\
\hline Chronic distal DVT & 12 & 12 \\
Chronic proximal DVT & 2 & 2 \\
Acute distal DVT & 2 & 11 \\
Acute proximal DVT & & 4 \\
History of pulmonary embolism & & \\
Anticoagulant treatment & & 2 \\
Low molecular weight heparin + warfarin & 11 & 7 \\
Warfarin & 13 & 15 \\
Non-warfarin oral anticoagulant & 2 & 4 \\
Low molecular weight heparin & 4 & 4 \\
ASA (acetylsalicylic acid) &
\end{tabular}

DVT: Deep venous thrombosis; Two patients used ASA with warfarin.

Table 3. Changes in oxidative damage, vitamin A and beta-carotene parameters between deep venous thrombosis patients and healthy controls

\begin{tabular}{lccccc}
\hline & Patient & & Control & \\
\cline { 2 - 2 } \cline { 5 - 5 } Parameters & Mean \pm SD & & Mean \pm SD & & $p$ \\
\hline Malondialdehyde $(\mathrm{nmol} / \mathrm{mL})$ & $2.4 \pm 0.5^{*}$ & & $1.2 \pm 0.4 \uparrow$ & & $<0.05$ \\
& & & $=0.000$ \\
Vitamin A $(\mu \mathrm{g} / \mathrm{dL})$ & $176.1 \pm 66.4^{*}$ & & $322.3 \pm 140.2 \uparrow$ & $<0.05$ \\
& & & & $=0.000$ \\
Beta-caroten $(\mu \mathrm{g} / \mathrm{dL})$ & $183.1 \pm 41.0$ & & $174.4 \pm 32.9$ & $>0.05$ \\
& & & $=0.297$ \\
\hline
\end{tabular}

SD: Standard deviation; $, \uparrow:$ The different letters in the same row show the statistical significance.
31 and 40 years, 25 were between 41 and 50 years, seven were between 51 and 60 years, and two were between 61 and 70 years. Six individuals in the control group had diabetes mellitus, four had hypertension, and 35 were smokers. Demographic characteristics were similar between the acute and chronic DVT patients. Demographic and clinical characteristics of the patients are shown in Table 1. Distribution of DVT patients according to gender and DVT therapy is summarized in Table 2.

For the comparison of all DVT patients and distal and proximal DVT patients with healthy individuals, the mean MDA levels significantly increased and the level of vitamin A significantly decreased in the

Table 4. Changes in oxidative damage, vitamin A and beta-carotene parameters between healthy controls and patients with distal deep venous thrombosis disease (Patient 1 )

\begin{tabular}{lccccc}
\hline & Patient 1 & & Control & \\
\cline { 2 - 2 } \cline { 5 - 5 } Parameters & Mean \pm SD & & Mean \pm SD & & $p$ \\
\hline Malondialdehyde $(\mathrm{nmol} / \mathrm{mL})$ & $2.9 \pm 0.3^{*}$ & & $1.1 \pm 0.5 \dagger$ & & $<0.05$ \\
& & & $=0.000$ \\
Vitamin A $(\mu \mathrm{g} / \mathrm{dL})$ & $138.4 \pm 28.5^{*}$ & & $278.9 \pm 54.5 \dagger$ & $<0.05$ \\
& & & $=0.001$ \\
Beta-caroten $(\mu \mathrm{g} / \mathrm{dL})$ & $163.2 \pm 50.4$ & & $159.1 \pm 44.5$ & $>0.05$ \\
& & & $=0.270$ \\
\hline
\end{tabular}

SD: Standard deviation; * $\uparrow:$ The different letters in the same row show the statistical significance.

Table 5. Changes in oxidative damage, vitamin A and beta-carotene parameters between patients with deep venous thrombosis disease in proximal (Patient 2) and healthy controls

\begin{tabular}{|c|c|c|c|}
\hline & Patient 2 & Control & \\
\hline Parameters & $\mathrm{Mean} \pm \mathrm{SD}$ & Mean $\pm S D$ & $p$ \\
\hline Malondialdehyde $(\mathrm{nmol} / \mathrm{mL})$ & $5.7 \pm 0.3^{*}$ & $2.1 \pm 0.4 \dagger$ & $\begin{aligned}<0.05 \\
=0.000\end{aligned}$ \\
\hline Vitamin $\mathrm{A}(\mu \mathrm{g} / \mathrm{dL})$ & $118.7 \pm 32.5^{*}$ & $248.5 \pm 60.5 \dagger$ & $\begin{aligned}<0.05 \\
=0.000\end{aligned}$ \\
\hline Beta-caroten $(\mu g / d L)$ & $164.1 \pm 49.0$ & $160.0 \pm 44.0$ & $\begin{aligned} &>0.05 \\
&= 0.439\end{aligned}$ \\
\hline
\end{tabular}

SD: Standard deviation; ${ }^{*},:$ The different letters in the same row show the statistical significance.

Table 6. Changes in oxidative damage, vitamin $\mathrm{A}$ and beta-carotene parameters between patients with distal deep venous thrombosis disease (Patient 1 ) with proximal deep venous thrombosis disease (Patient 2)

\begin{tabular}{lccccc}
\hline & Patient 1 & & Patient 2 & \\
\cline { 2 - 2 } \cline { 5 - 5 } Parameters & Mean \pm SD & & Mean \pm SD & & $p$ \\
\hline Malondialdehyde $(\mathrm{nmol} / \mathrm{mL})$ & $1.1 \pm 0.5$ & & $1.1 \pm 0.5$ & $>0.05$ \\
& & & & 0.631 \\
Vitamin A $(\mu \mathrm{g} / \mathrm{dL})$ & $172.2 \pm 37.5$ & & $174.9 \pm 27.5$ & $>0.05$ \\
& & & $=0.534$ \\
Beta-caroten $(\mu \mathrm{g} / \mathrm{dL})$ & $186.0 \pm 28.0$ & & $185.3 \pm 37.0$ & $>0.05$ \\
& & & $=0.872$ \\
\hline
\end{tabular}

SD: Standard deviation 


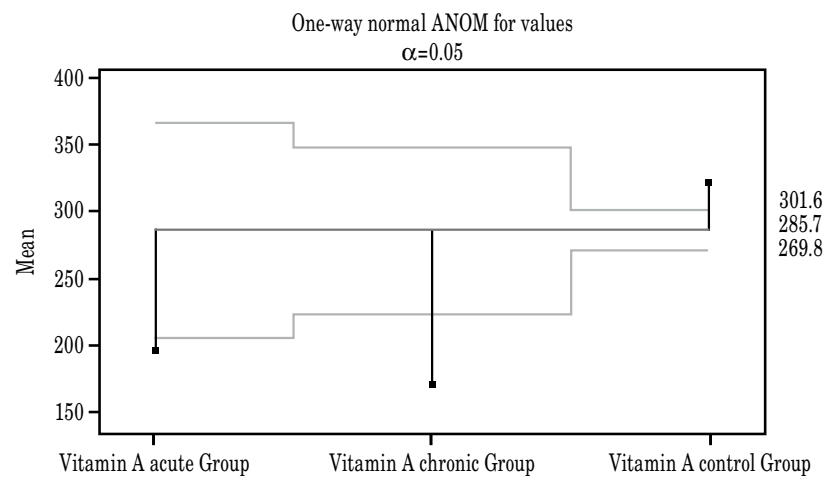

\begin{tabular}{|l|l|c|c|c|c|c|}
\hline \multirow{3}{*}{$\begin{array}{l}\text { Variable } \\
\text { group }\end{array}$} & Groups & $\mathrm{N}$ & $\mathrm{N}^{*}$ & Mean & $\mathrm{r}$ & $\mathrm{SD}$ \\
\cline { 2 - 7 } & Vitamin A acute & 13 & 5 & 196.4 & 22.6 & 81.3 \\
\cline { 2 - 7 } & Vitamin A chronic & 20 & 10 & 169.6 & 11.7 & 52.4 \\
\cline { 2 - 7 } & Vitamin A control & 95 & 5 & 322.3 & 14.4 & 140.2 \\
\hline
\end{tabular}

Figure 2. Comparison of vitamin A levels in acute and chronic deep venous thrombosis patients and healthy controls. The mean vitamin A levels of the control group were significantly higher than the acute and chronic group $(\mathrm{p}=0.00)$. On the other hand, the acute and chronic groups exhibited a similar structure.

ANOM: Analysis of means; SD: Standard deviation.

patient group $(\mathrm{p}<0.05)$ (Tables $3-5)$. No statistically significant difference in the MDA, vitamin $A$, and $\beta$-carotene levels was found between the patients with distal DVT and proximal DVT disease $(p>0.05)$ (Table 6). However, the mean vitamin A levels of the control group were significantly higher than the acute and chronic group $(p=0.001)$. On the other hand, the acute and chronic groups exhibited a similar structure (Figure 2). The levels of MDA in the acute group were significantly higher than the other two groups $(p=0.001)$. The MDA acute group had the highest levels, while the control group had the lowest levels (Figure 3).

\section{DISCUSSION}

In our study, thrombosis of the deep leg veins could be related to the decreased t-PA synthesis as a result of vitamin A which was also significantly lower than healthy individuals. In addition, in all DVT patients, the patients with distal and proximal DVT disease had a significant increase in the MDA level compared to healthy individuals and this increase was considered effective in DVT disease.

Reduced plasma fibrinolytic activity is associated with increased thromboembolic events. ${ }^{[21,22]}$ Human endothelial cells are an important source of t-PA and PAI-1. ${ }^{[23]}$ In a study, it was shown that retinoic acid increased $\mathrm{t}$-PA synthesis without changing

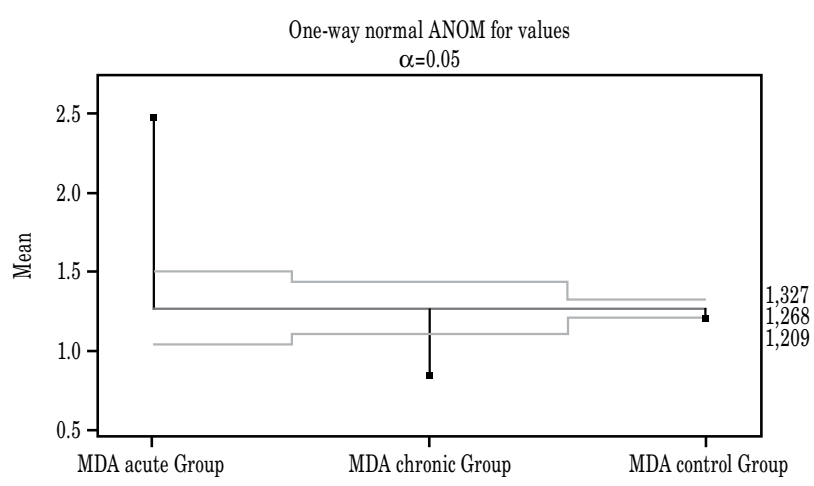

\begin{tabular}{|l|l|c|c|c|c|c|}
\hline $\begin{array}{l}\text { Variable } \\
\text { group }\end{array}$ & Groups & $\mathrm{N}$ & $\mathrm{N} *$ & Mean & $\mathrm{r}$ & $\mathrm{SD}$ \\
\cline { 2 - 7 } & MDA acute & 17 & 0 & 2,465 & 0,104 & 0,441 \\
\cline { 2 - 7 } & MDA chronic & 30 & 0 & 0,8443 & 0,0692 & 0,3792 \\
\cline { 2 - 7 } & MDA control & 99 & 1 & 1,1783 & 0,0439 & 0,4364 \\
\hline
\end{tabular}

Figure 3. Comparison of MDA levels in acute and chronic deep venous thrombosis patients and healthy controls. The mean MDA levels were significantly higher in the acute groups than the other two groups $(\mathrm{p}=0.00)$. The acute group had the highest MDA levels, while the control group had the lowest levels.

ANOM: Analysis of means; SD: Standard deviation; MDA: Malondialdehyde.

the production of PAI-1. ${ }^{[12]}$ The induction of $\mathrm{t}-\mathrm{PA}$ synthesis with retinoic acid depends on time and concentration, and micromolar concentration has been reported to cause physiological responses in animals and inhibit the colony formation of malignant cells. ${ }^{[24]}$ When inducing t-PA synthesis for the protein synthesis, retinoic acid increases the synthesis in messenger ribonucleic acid. ${ }^{[12]}$ Retinoids, including retinoic acid and vitamin $\mathrm{A}$, are known to be effective in many biological phenomena, such as cell growth and differentiation. ${ }^{[12]}$ The physiological role and potential pathophysiological condition of the t-PA induced by the synthesis of retinoic acid is important to maintain the homeostatic balance between thrombosis and thrombolysis. ${ }^{[12]}$

In many studies, it has been demonstrated that the decrease in vitamin A levels in thrombosis is effective in increasing the MDA levels. However, although previous studies mostly focused on general thrombosis, the main strength of our study is that venous thrombosis cases were included. Of note, there is a very limited number of studies on venous thrombosis in the literature. In consistent with the results of previous studies examining vitamin A and MDA, our study led us to explain the relationship between MDA and vitamin $A$ in this patient population.

Beta-carotene is a naturally-occurring vitamin A precursor obtained from certain fruits and vegetables 
with potential antineoplastic and chemopreventive activities. ${ }^{[25]}$ In our study, there was no statistically significant difference in the $\beta$-carotene levels between the patient and control groups. However, the main limitation to this study is that there was no information about whether there was an enzymatic deficiency in the pathway converting the $\beta$-carotene to vitamin A. Relatively small sample size is the other limitation. In future studies, the importance of determining and using the therapeutic dose of vitamin A, which is an antioxidant in DVT patients and effective in t-PA synthesis metabolism, should be revealed in large-scale, prospective, clinical researches to develop a more effective treatment method for these patients.

In conclusion, all DVT patients including distal and proximal DVT had a significant increase in the MDA levels and a significant decrease in vitamin A levels, compared to healthy individuals. These findings highlight the importance of vitamin A in reducing the risk factors for thrombosis. Based on these study results, we speculate that decreased vitamin A levels may play a role in DVT thrombosis. Also, significantly lower levels of vitamin A in DVT patients with increased MDA levels may have contributed to the formation and progression of DVT disease with the oxidative damage it created.

\section{Declaration of conflicting interests}

The authors declared no conflicts of interest with respect to the authorship and/or publication of this article.

\section{Funding}

The authors received no financial support for the research and/or authorship of this article.

\section{REFERENCES}

1. Naess IA, Christiansen SC, Romundstad P, Cannegieter SC, Rosendaal FR, Hammerstrøm J. Incidence and mortality of venous thrombosis: a population-based study. J Thromb Haemost 2007;5:692-9.

2. Veeger NJ, Piersma-Wichers M, Tijssen JG, Hillege HL, van der Meer J. Individual time within target range in patients treated with vitamin $\mathrm{K}$ antagonists: main determinant of quality of anticoagulation and predictor of clinical outcome. A retrospective study of 2300 consecutive patients with venous thromboembolism. Br J Haematol 2005;128:513-9.

3. McCully KS. Vascular pathology of homocysteinemia: implications for the pathogenesis of arteriosclerosis. Am J Pathol 1969;56:111-28.

4. Lijfering WM, Rosendaal FR, Cannegieter SC. Risk factors for venous thrombosis - current understanding from an epidemiological point of view. $\mathrm{Br} \mathrm{J}$ Haematol 2010;149:824-33.

5. Bhupathiraju SN, Tucker KL. Coronary heart disease prevention: nutrients, foods, and dietary patterns. Clin Chim Acta 2011;412:1493-514.

6. Lock K, Pomerleau J, Causer L, Altmann DR, McKee M. The global burden of disease attributable to low consumption of fruit and vegetables: implications for the global strategy on diet. Bull World Health Organ 2005;83:100-8.

7. Myung SK, Ju W, Cho B, Oh SW, Park SM, Koo BK, et al. Efficacy of vitamin and antioxidant supplements in prevention of cardiovascular disease: systematic review and meta-analysis of randomised controlled trials. BMJ 2013;346:f10.

8. Brøndum-Jacobsen $\mathrm{P}$, Benn $\mathrm{M}$, Tybjaerg-Hansen A, Nordestgaard BG. 25-Hydroxyvitamin D concentrations and risk of venous thromboembolism in the general population with 18,791 participants. J Thromb Haemost 2013;11:423-31.

9. Glynn RJ, Ridker PM, Goldhaber SZ, Zee RY, Buring JE. Effects of random allocation to vitamin E supplementation on the occurrence of venous thromboembolism: report from the Women's Health Study. Circulation 2007;116:1497-503.

10. Brodin E, Lerstad G, Grimnes G, Brækkan SK, Vik A, Brox J, et al. Serum levels of vitamin D are not associated with future risk of venous thromboembolism. The Tromsø Study. Thromb Haemost 2013;109:885-90.

11. Bulger EM, Helton WS, Clinton CM, Roque RP, Garcia I, Maier RV. Enteral vitamin E supplementation inhibits the cytokine response to endotoxin. Arch Surg 1997;132:1337-41.

12. Marchetti M, Vignoli A, Bani MR, Balducci D, Barbui T, Falanga A. All-trans retinoic acid modulates microvascular endothelial cell hemostatic properties. Haematologica 2003;88:895-905.

13. Rickles RJ, Darrow AL, Strickland S. Molecular cloning of complementary DNA to mouse tissue plasminogen activator mRNA and its expression during F9 teratocarcinoma cell differentiation. J Biol Chem 1988;263:1563-9.

14. Vučković BA, van Rein N, Cannegieter SC, Rosendaal FR, Lijfering WM. Vitamin supplementation on the risk of venous thrombosis: results from the MEGA case-control study. Am J Clin Nutr 2015;101:606-12.

15. Glowinski J, Glowinski S. Generation of reactive oxygen metabolites by the varicose vein wall. Eur J Vasc Endovasc Surg 2002;23:550-5.

16. Demirci S, Sekeroğlu MR, Noyan T, Köçeroğlu R, Soyoral YU, Dülger $\mathrm{H}$, et al. The importance of oxidative stress in patients with chronic renal failure whose hypertension is treated with peritoneal dialysis. Cell Biochem Funct 2011;29:249-54.

17. Placer ZA, Cushman LL, Johnson BC. Estimation of product of lipid peroxidation (malonyl dialdehyde) in biochemical systems. Anal Biochem 1966;16:359-64.

18. Suzuki J, Katoh N. A simple and cheap methods for measuring serum vitamin A in cattle using only a spectrophotometer. Nihon Juigaku Zasshi 1990;52:1281-3. 
19. Mendeş M, Yiğit S. Comparison of ANOVA-F and ANOM tests with regard to type I error rate and test power. Journal of Statistical Computation and Simulation 2013;83: 2093-104.

20. Mendeş M, Yiğit S. An alternative approach for multiple comparison problems when there are a large number of groups: ANOM technique. The Journal of Animal \& Plant Sciences 2018;28:1074-9.

21. Nilsson IM, Ljungnér H, Tengborn L. Two different mechanisms in patients with venous thrombosis and defective fibrinolysis: low concentration of plasminogen activator or increased concentration of plasminogen activator inhibitor. Br Med J 1985;290:1453-6.

22. Juhan-Vague I, Valadier J, Alessi MC, Aillaud MF,
Ansaldi J, Philip-Joet C, et al. Deficient t-PA release and elevated PA inhibitor levels in patients with spontaneous or recurrent deep venous thrombosis. Thromb Haemost 1987;57:67-72.

23. Schleef RR, Loskutoff DJ. Fibrinolytic system of vascular endothelial cells. Role of plasminogen activator inhibitors. Haemostasis 1988;18:328-41.

24. Moon RC, Itri LM. In the retinoids. In: Sporn MB, Roberts AB, Goodman DWS, editors. The Retinoids. Vol. II. New York: Academic Press; 1984. p. 327-71.

25. U.S. National Library of Medicine National Center for Biotechnology Information. Available at: https://pubchem. ncbi.nlm.nih.gov/compound/beta-Carotene. 